\title{
ROLE OF LABETALOL IN ACUTE MYOCARDIAL INFARCTION
}

\author{
A.D. TIMMIS, M.B. FOWLER, N.S.V. JAGGARAO, R. VINCENT \\ \& D.A. CHAMBERLAIN \\ Department of Cardiology, Royal Sussex County Hospital, Brighton, BN2 5BE, UK
}

1 The role of labetalol in managing acute myocardial infarction is reviewed.

2 After intravenous infusion labetalol lowers blood pressure in patients with increased blood pressure associated with acute myocardial infarction.

3 Although average heart rate was decreased, cardiac index fell only slightly and stroke index was substantially unchanged.

4 In patients whose pretreatment pulmonary artery end-diastolic pressures were increased, labetalol induced decreases, whereas in the presence of normal pressures, these were unchanged.

5 It is concluded that labetalol infusion in patients with acute myocardial infarction is unlikely to precipitate heart failure and is likely to be of value in reducing myocardial oxygen requirement.

\section{Introduction}

The use of labetalol as an anti-hypertensive agent is logical and is accepted. The combination of $\alpha$ adrenoceptor blockade and $\beta$-adrenoceptor blockade also seems applicable for at least some patients with acute and chronic ischaemic heart disease. But evaluation for this indication is incomplete. We have used labetalol for patients with acute myocardial infarction associated with hypertension. In this communication we outline the reasons which prompted us to use labetalol, and we present the haemodynamic effects observed in a small group of the patients who were treated.

The late prognosis in infarction depends mainly on the area of muscle necrosis, but this is not determined irrevocably in the early hours following coronary occlusion (Braunwald \& Moroko, 1974). Some heart muscle remains healthy and some infarcted muscle is inevitably blighted, but between these zones there exists an area of jeopardized muscle which may recover or may not. Its fate depends on the balance between myocardial oxygen supply and the oxygen demand for its metabolic needs.

Oxygen supply depends on three factors. First, heart rate, because the slower the rate the longer the duration of diastole which promotes flow in the larger coronary arteries. Second, the diastolic blood pressure, which permits perfusion of the coronary arteries. Third, the state of the lumen in the coronary arteries which will be compromised after infarction by organic obstruction, and at least in the early stages by reactive spasm.

Myocardial oxygen requirement also depends on three principal factors (Sonnenblick et al., 1965) of

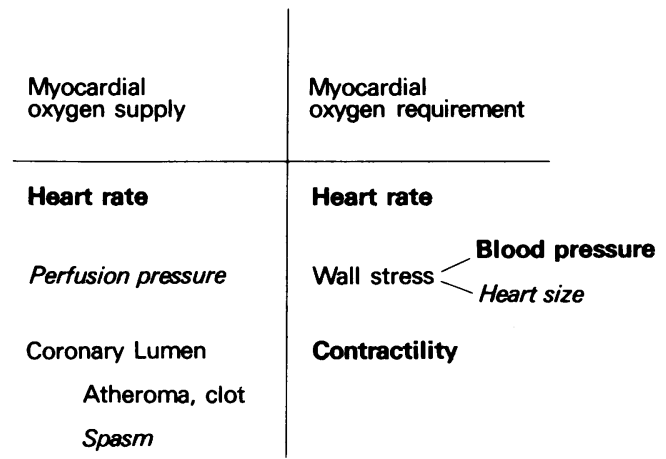

Figure 1 Effects of $\beta$-blocking agents on determinants of myocardial oxygen supply and requirements. Factors which are influenced favourably are in bold type, those influenced unfavourably in italics.

which heart rate is again one; here the slower the rate the less the metabolic requirement. Wall tension is a second factor, and this in turn is a function of blood pressure and heart size. The bigger a sphere the more energy is required to generate an intracavity pressure. The third variable is contractility which is a measure of the speed of contraction; the faster it occurs the more extravagant it is in energy requirement.

Using this scheme the favourable and the adverse effects of $\beta$-adrenoceptor blockade in infarction become apparent. All the factors mentioned above are influenced, except for the organic obstruction. In Figure 1 the favourable effects are in heavy type and the unfavourable effects in italics. On theoretical and experimental grounds it has been believed that the beneficial actions outweigh in importance the ones which may be deleterious. 
Any lowering of perfusion pressure will be relatively unimportant, but the increase in heart size must augment myocardial oxygen requirement. The greater fibre length during $\beta$-blockade is a consequence of impaired contractility; it is associated with increased filling pressure which can - in the presence of heart disease - be sufficient to precipitate the clinical manifestations of heart failure. The importance of spasm has been under-rated in the past. We now believe it is an important complicating or even initiating factor in infarction (Maseri et al., $1978)$. Since $\beta$-adrenergic activity dilates the coronary arteries, blockade of the $\beta$-receptors is likely to have an adverse effect on blood flow.

The effects on mortality of early intervention with $\beta$-adrenoceptor-blocking agents in patients with myocardial infarction has recently been reviewed by Hampton (1981), and is shown in Figure 2. Any trial with a convincing beneficial result would have a bar set well to the right and clear of the zero line, but none does so. Therefore we have no evidence that $\beta$-blockade alone influences mortality in early intervention studies. Two recent studies using intravenous atenolol and propranolol respectively indicated some limitation of infarct size as a result of drug therapy but we do not yet have data to confirm a beneficial prognostic effect (Yusuf et al., 1980; Peter et al., 1978).

We may question the reasons why $\beta$-adrenoceptor blockade is disappointing as an early therapeutic intervention after infarction. In addition to the possible precipitation of heart failure in those with severly impaired myocardial function and the possible adverse effect on coronary flow by increased coronary spasm mentioned above, two other possible complications must be noted. A critically low cardiac output may be further reduced by $\beta$-blockade, and disorders of impulse formation or conduction caused by ischaemia may also be worsened.

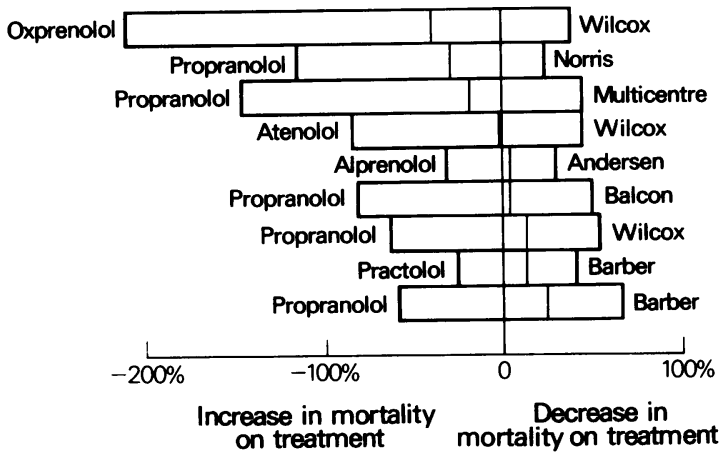

Figure 2

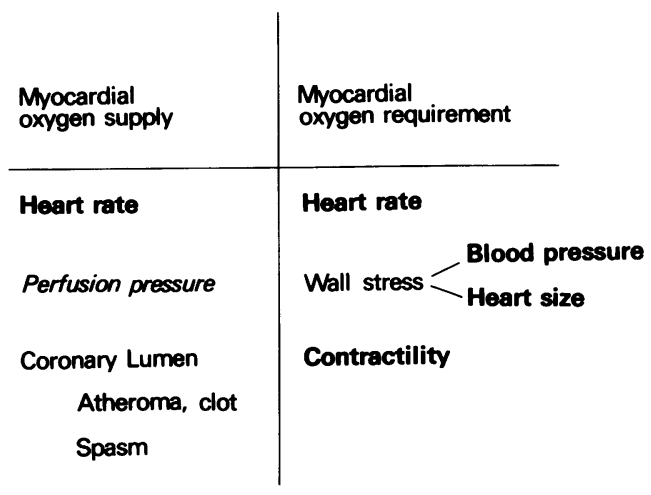

Figure 3 Effects of $\beta$-blocking agents on determinants of myocardial oxygen supply and requirements. Factors which are influenced favourably are in bold type. those influenced unfavourably in italics.

Labetalol should have a more favourable profile of expected effects on the metabolic balance of the ischaemic heart, because of the addition of $\alpha$ blocking effects (Figure 3). A reduction in afterload may permit a decrease in heart size despite diminished contractility, but this remains to be demonstrated. Moreover, blockade of both $\alpha$ - and $\beta$-receptors will tend to neutralize any effect on coronary spasm; future studies may show whether the net effect is slightly to decrease spasm or slightly to increase it. Apart from metabolic effects some recent studies (Sheridan et al., 1980) suggest that $\alpha$-adrenoceptor stimulation can generate some arrhythmias, implying a further possible advantage of labetalol over conventional $\beta$-blockers in protecting the ischaemic myocardium. There is still need for a word of caution. Blood pressure drops on labetalol can sometimes be steep, and perfusion pressure may be seriously impaired particularly if excessive doses are given.

These theoretical considerations led us to use labetalol first in patients with myocardial infarction which was complicated by hypertension. In these at least we were not concerned about adverse effects from undue reduction in perfusion pressure, although we always started treatment at relatively low infusion rates and avoided bolus injections. We studied seven patients with systolic pressures greater than $160 \mathrm{mmHg}$, sustained for at least $4 \mathrm{~h}$ after admission.

Labetalol was infused initially at $500 \mu \mathrm{g} / \mathrm{min}$, increasing by $500 \mu \mathrm{g}$ every $30 \mathrm{~min}$ until an endpoint was reached: either a systolic pressure of $120 \mathrm{mmHg}$ or a fall of $60 \mathrm{mmHg}$, whichever occurred first. Haemodynamic measurements were made at an average infusion rate of $1 \mathrm{mg} / \mathrm{min}$, and measure- 


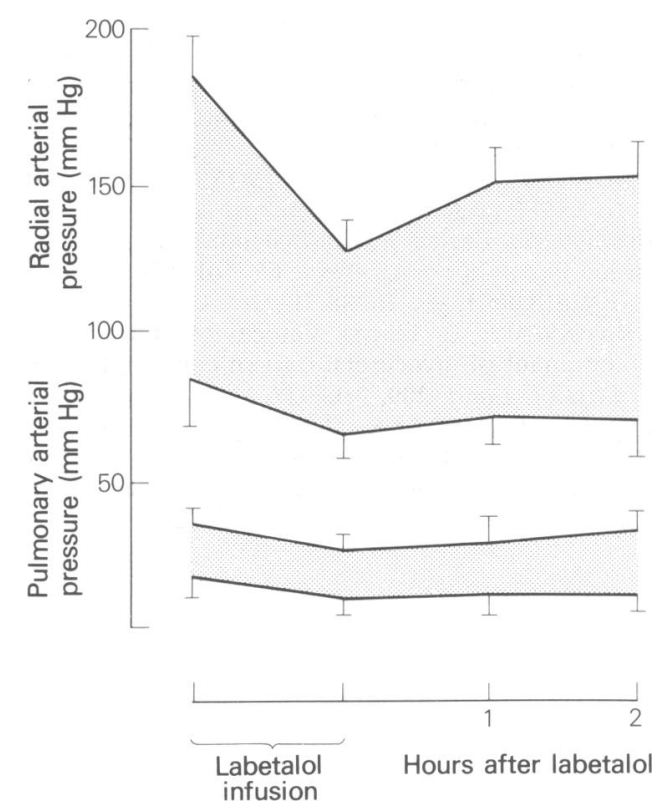

Figure 4 Radial and pulmonary artery pressure before and after labetalol infusion. $N=7$. Values expressed as mean \pm s.e.mean.

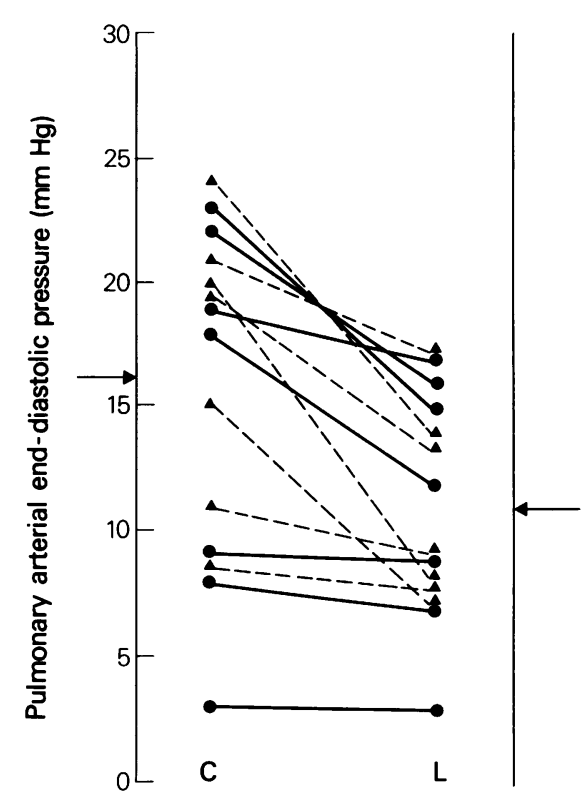

Figure 5 Effect of labetalol infusion on pulmonary artery end-diastolic pressure in patients with acute myocardial infarction. Solid lines refer to the present study and the interrupted lines to data derived from the study of Marx and Reid (1979), included with the permission of the authors. $N=14$. Arrows indicate means. C, Control; L, labetalol.

Its $\alpha$-blocking action may indeed promote an improvement in heart failure because of vasodilation and afterload reduction.

We conclude that an infusion of labetalol does exert some $\beta$-blocking effect in patients with acute infarction but unlike conventional $\beta$-blocking agents, it does not precipitate heart failure. It reduces cardiac output only slightly and we postulate that it is unlikely to worsen coronary spasm. It may, however, exacerbate conduction disorders in those who are vulnerable and we must remember that excessive hypotension will reduce coronary flow.

Conservation of jeopardized myocardium is a goal that all cardiologists seek in order to improve the long-term prognosis after infarction. Labetalol has the characteristics of a drug which might be useful in this respect and further studies are warranted.

This work was carried out while Dr Jaggarao held a British Heart Foundation overseas visiting fellowship. We thank the European Heart Journal for permission to reproduce Figures 4 and 5 . 


\section{References}

BRAUNWALD, E. \& MOROKO, P.R. (1974). The reduction of infarct size - an idea whose time (for testing) has come. Circulation, 50, 206-209.

HAMPTON, J.R. (1981). The use of $\beta$-blockers for the reduction of mortality after myocardial infarction. Eur. Heart J. (in press).

MARX, P.G. \& REID, D.S. (1979). Labetalol infusion in acute myocardial infarction with systemic hypertension. Br. J. clin. Pharmac., 8, suppl. 2, 233S-238S.

MASERI, A., L'ABBATE, A., BAROLDI, G., CHIERCHIA, S., MARZILLI, M., BALLESTRA, A.M., SEVERI, S., PARODI, O., BIAGINI, A., DISTANTE, A. \& PESOLA, A. (1978). Coronary vasospasm as a possible cause of myocardial infarction. New Eng. J. Med., 299, 12711277.
PETER, T., NORRIS, R.M., CLARKE, E.D., HENG, M.K. SINGH, B.N., WILLIAMS, B., HOWELL, D.R. \& AMBLER, P.K. (1978). Reduction of enzyme levels by propranolol after acute myocardial infarction. Circulation, 57, 1091-1095.

SHERIDAN, D.J., PENKOSKE, P.A., SOBEL., B.E. \& CORR, P.B. (1980). Alpha adrenergic contribution to dysrhythmia curing myocardial infarction and reperfusion in cats. J. clin. Invest., 65, 161-171.

SONNENBLICK, E.H., ROSS, J., Jr., COVELL, J.W. \& BRAUNWALD, E. (1965). Velocity of contraction as a determinant of myocardial oxygen consumption. Am. J. Physiol. Lond. 209, 919-927.

YUSUF, S., RAMSDALE, D., PETO, R., FURSE, L., BENNETT, D., BRAY, C. \& SLEIGHT, P. (1980). Early intravenous atenolol treatment in suspected acute myocardial infarction. Lancet, 2, 273-276. 